\title{
ROLETA DO NOX: UMA ATIVIDADE LÚDICA EM QUÍMICA NO CONTEÚDO DE NÚMERO DE OXIDAÇÃO
}

\section{NOX ROOL: A CHEMICAL ACTIVITY IN CHEMISTRY IN THE CONTENT OF OXIDATION NUMBER}

Natália Kelly da Silva Araújo; ${ }^{1}$ Ayrton Matheus da Silva Nascimento ${ }^{2}$; Gabriela Rejane Silva de Medeiros ${ }^{3}$; Danielly Francielly dos Santos Silva ${ }^{4}$; Kilma da Silva Lima Viana ${ }^{5}$

\section{RESUMO}

O emprego de jogos didáticos nas aulas de Química é um desafio para todo o professor desta área do conhecimento, pois visa uma ponte entre o lúdico e a teoria, facilitando e criando um ambiente favorável ao conhecimento. Assim, foi criado o jogo "Roleta do NOX", onde tem um objetivo de identificar o Número de Oxidação (NOX) de cada elemento químico, ou seja, substâncias simples e compostos de maneira que os discentes compreendam esta temática de forma lúdica. Utilizamos como orientação para construção deste jogo os estudos de Fonseca (2016). Esta pesquisa mostra a preparação até a experiência de um jogo didático, intitulado "Roleta do NOX" utilizando como metodologia o CEK (Ciclo da Experiência Kellyana) proposto por George Kelly (1963). Este jogo é direcionado para os estudantes do Ensino Médio, no conteúdo de Número de Oxidação. Este recurso didático foi criado Instituto Internacional Despertando Vocações (IIDV) ligado ao Programa Internacional Despertando Vocações para Licenciaturas (PDVL) articulado ao Grupo de Trabalho (GT) de Jogos Didáticos no Ensino de Química, e a vivência foi realizada numa turma de $2^{\circ}$ ano do Ensino Médio, na qual é parceira do programa, na cidade de Recife - Pernambuco. Dessa forma, foi usado como estrutura metodológica o ciclo da experiência Kellyana (CEK) o qual é embasado pela Teoria dos Construtos Pessoais de George Kelly (1963). Nesta vivência foi inegável que cerca $82 \%$ dos alunos acertaram as perguntas referente ao NOX. A partir dos resultados deste trabalho, pode-se ressaltar que os estudantes têm a oportunidade de participar ativamente de toda a atividade, fazendo uso de seus conhecimentos prévios, realizando reflexões e discussões com os colegas e o professor favorecendo a interação aluno-aluno e alunoprofessor.

Palavras-Chave: Físico-Química, CEK, Jogo Didático, Ensino Médio

\begin{abstract}
\footnotetext{
${ }^{1}$ Graduanda em Química, IFPE - Campus Vitória, nataliakellybs@ gmail.com

${ }^{2}$ Especialista em Ensino de Química, UCAM - Prominas, ayrthon.matheus@gmail.com

${ }^{3}$ Graduanda em Química, IFPE - Campus Vitória, medeirosgabriela32@ yahoo.com.br

${ }^{4}$ Graduanda em Química, IFPE - Campus Vitória, danysantos023@ outlook.com

${ }^{5}$ Doutora em Ensino de Ciências, IFPE - Campus Vitória, kilma.viana71@ @mail.com
}

The use of didactic games in Chemistry classes is a challenge for all the teacher of this area of knowledge, since it aims at a bridge between play and theory, facilitating and creating an environment conducive to knowledge. Thus, the game "NOX roulette" was created, where it aims to identify the Oxidation Number (NOX) of each chemical element, that is, simple and compound substances so that the students understand this theme in a playful way. We use as orientation to build this game the studies of Fonseca (2016). This research shows the preparation to the experience of a didactic game, entitled "NOX roulette" using as methodology the CEK (Kellyana Experience Cycle) proposed by George Kelly (1963). This game is aimed at high school students in the content of Oxidation Number. This didactic resource was created International Institute Awakening Vocations (IIDV) linked to the 
International Program Awakening Vocations for Undergraduate Courses (PDVL) articulated to the Working Group (GT) of Didactic Games in the Teaching of Chemistry, and the experience was realized in a class of $2^{\circ}$ year of the High School, in which she is a partner of the program, in the city of Recife - Pernambuco. Thus, the Kellyana experiment cycle (CEK), which is based on George Kelly's Theory of Personal Construsions (1963), was used as a methodological framework. In this experience, it was undeniable that about $82 \%$ of the students answered questions about NOX. From the results of this work, it is possible to emphasize that the students have the opportunity to actively participate of all the activity, making use of their previous knowledge, realizing reflections and discussions with the colleagues and the teacher favoring the interaction student-student and student -teacher.

Keywords: Physical Chemistry, CEK, Didactic Game, High School

\section{INTRODUÇÃO}

O conteúdo de Química NOX (Número de Oxidação) trata-se do estudo que corresponde à carga elétrica real do íon, ou seja, é o número de elétrons (e-) que o átomo realmente perdeu (oxidação) ou ganhou (redução) durante uma reação química por oxirredução (Fonseca, 2016), sendo um conteúdo que é bastante abordado na sala de aula no Ensino Médio, devido a sua expansiva cobrança no ENEM (Exame Nacional do Ensino Médio) e vestibulares tradicionais, é um conteúdo de vital importância e relativamente não muito atrativo para os alunos, devido ao conhecimento básico das operações matemáticas, visto que trata-se de entender cada carga de um átomo, diante disso, os professores de química devem fazer uso de metodologias diferenciadas em sua prática de ensino, com o propósito de despertar a curiosidade dos estudantes, adquirindo a participação ativa dos sujeitos ao longo da atividade. Desta forma, além de contribuir no processo de aprendizagem, revelara-se como uma atividade que será lembrada pelos estudantes exatamente por estar sendo algo diferente do habitual.

A educação brasileira apesar das diversas tentativas em busca da implementação de materiais para apoio didático ainda necessita de muita dedicação e esforço de todos os membros que estão envolvidos na escola para que os recursos utilizados sejam adaptados às condições e realidade dos alunos, recursos que os estimulem e facilitem o aprendizado nas disciplinas, principalmente na disciplina de ciências que apresentam muitos conceitos e termos que não estão presentes no cotidiano dos alunos, tendo em vista as dificuldades encontradas pelos discentes para aprenderem os conceitos científicos no ensino de Ciências os estagiários desenvolveram atividades lúdicas para facilitar o ensino na sala de aula (SANTOS; GUIMARÃES, 2010).

Para obter um ensino mais eficiente aperfeiçoou novas técnicas didáticas consistindo numa prática inovadora e prazerosa. Dentre essas técnicas temos o lúdico, um recurso didático 
dinâmico que garante resultados eficazes na educação, apesar de exigir extremo planejamento e cuidado na execução da atividade elaborada e cabe ao professor auto avaliar-se e avaliar as suas práticas de ensino, de acordo com Freire, o professor tem o papel de estimular e contribuir para incentivar a criatividade em sala de aula, tanto com suas metodologias para ensinar, quanto para mostrar para os alunos que as limitações devem ser enfrentadas e superadas. Assim, a docência se pauta nos ensinamentos de FREIRE (1996), quanto ao que postula na epígrafe acima: "Ensinar não é transferir conhecimento, mas criar as possibilidades para a sua própria produção ou a sua construção" (p.27).

Brito afirma que apesar de jogos educacionais envolvendo química muitas vezes serem complexos, pode se tornar uma forma alternativa para contribuir de forma favorável para o desenvolvimento educacional. Quanto mais desafiador se apresentar a aprendizagem, maiores serão as chances de os estudantes enriquecerem seus conhecimentos, dos outros e da realidade e inserir o conteúdo aprendido na análise cotidiana BRITO (2017).

Diante deste cenário o proposto artigo tem a finalidade de contribuir de forma significativa com um jogo didático chamado "Roleta do NOX", que tem por objetivo auxiliar o professor nas aulas de NOX, assunto pertinente à disciplina de Química, ajudando de maneira lúdica os alunos a entenderem melhor tal assunto, o jogo dispõe de perguntas altamente contextualizadas e envolventes.

\section{FUNDAMENTAÇÃO TEÓRICA}

Segundo DONDI e MORETTI (2007) os jogos educativos possuem objetivos didáticos explícitos podendo ser adotados para melhorar, apoiar ou promover os processos de aprendizagem. Dessa forma, para mudar a situação que temos hoje no ambiente escolar, se faz necessário que os professores procurem melhorar suas estratégias de ensino para que os alunos se interessem mais pelas aulas. Tornando as aulas antes cansativas, em aulas dinâmicas com as práticas e discursivas proporcionando aos estudantes um melhor entendimento e um aumento no interesse pelo conteúdo teórico. A exploração do lúdico, pode se tornar uma técnica de facilitação na elaboração de conceitos e no reforço dos conteúdos (FIALHO, 2007).

Conforme CUNHA (2012), durante muito tempo, acreditava-se que a aprendizagem ocorria pela memorização e reprodução de conteúdo e os estudantes que não aprendiam, eram os responsáveis pelo próprio insucesso, desse modo, o objetivo do ensino sistematizado era eternizar teorias através das gerações. Em consequência disto, acaba se por gerar estudantes com dificuldades em aprender, desinteressados no que se refere à participação dos momentos de aula e possuidores de deficiências no que concerne ao relacionar aquilo que está sendo 
estudando com fenômenos presentes em seu cotidiano. Vieira afirma que é sabido também que aulas com atividades diferenciadas, onde o estudante tem contato com o objeto de estudo e consequentemente se torna o protagonista do processo de ensino-aprendizagem, o deixam mais atento e participativo.

Sendo assim, a utilização de materiais didáticos sobre um assunto específico de Química como jogos, livros, experimentos, vídeos, levando em consideração o conhecimento do aluno, seu modo de ser, de agir, de estar, além de sua dinâmica pessoal, auxilia a prática do professor, pois o trabalho docente não se trata apenas de um conteúdo, mas de um processo que envolve um conjunto de pessoas na construção de saberes VIEIRA (2018).

Atividade lúdica é todo e qualquer movimento que tem como objetivo produzir prazer quando de sua execução, ou seja, divertir o praticante. Se há regras, essa atividade lúdica pode ser considerada um jogo (SOARES, 2008). Fazendo tal uso o professor/educador será capaz de despertar em seu aluno, com o uso do jogo, o interesse em querer apreender, buscando querer adquirir novos conhecimentos, sendo essas feitas de forma agradável e prazerosa, podendo sempre explorar situações do cotidiano do aluno, outro ponto positivo que os jogos trazem é a socialização e comunicação dos alunos entre si ou para com o seu professor, pois na maioria dos jogos, os estudantes participam em grupos onde eles buscam juntas as soluções.

Desta forma é possível perceber que as atividades lúdicas colaboram não somente para o ensino-aprendizagem escolar, mas também proporcionam competências sociais aos alunos. Este pensamento é complementado por Rodrigues (2001), segundo ele o jogo responde as necessidades lúdicas, intelectual e afetiva, estimulando a vida social e tornando-se, assim, um grande contribuinte na aprendizagem.

\section{METODOLOGIA}

Esta pesquisa foi desenvolvida pelo Instituto Internacional Despertando Vocações (IIDV) ligado ao Programa Internacional Despertando Vocações para Licenciaturas (PDVL) articulado ao Grupo de Trabalho (GT) de Jogos Didáticos no Ensino de Química e dos professores da área Pedagógica do programa.

\section{Caracterização do Campo da Pesquisa}

A pesquisa foi concretiza no Geração Colégio e Curso (GCC), na Cidade de Recife, no estado de Pernambuco. Os sujeitos foram 30 (trinta) estudantes do $2^{\circ}$ ano do ensino médio.

\section{Instrumentos de Coleta}


Foram empregados como instrumentos de pesquisa questionário com os discentes, observação e registro da vivência do Ciclo da Experiência Kellyana - CEK, (KELLY, 1955). Com isso, utilizamos como base metodológica o ciclo da experiência Kellyana (CEK) o qual é fundamentado na Teoria dos Construtos Pessoais de George Kelly (1963).

\section{Aplicação do Ciclo da Experiência Kelly (CEK) - "Roleta do NOX"}

- Antecipação: neste momento os estudantes foram direcionados a responder um questionário com 05 (cinco) perguntas sobre o conteúdo de NOX com a finalidade de levantar os conhecimentos prévios sobre esta temática.

$\mathbf{1}^{\mathrm{a}}$ Questão: (UFSCAR-SP) Os números de oxidação do enxofre em $\mathrm{H}_{2} \mathrm{~S}, \mathrm{~S}_{8}$ e $\mathrm{Na}_{2} \mathrm{SO}_{3}$ são, respectivamente,
a) $+2,-8$ e -4 .
b) -2 , zero, e +4 .
c) zero, -4 e +3 .
d) $+1,-2$ e -3 .
e) $-6,+8$ e -5 .

$2^{\text {a }}$ Questão: (ITA-SP) Assinale a opção relativa aos números de oxidação corretos do átomo de cloro nos compostos $\mathrm{KClO}_{2}, \mathrm{Ca}(\mathrm{ClO})_{2}, \quad \mathrm{Mg}\left(\mathrm{ClO}_{3}\right)_{2}$ e $\mathrm{Ba}\left(\mathrm{ClO}_{4}\right)_{2}$, respectivamente
a) $-1,-1,-1$ e -1
b) $+3,+1,+2$ e +3
c) $+3,+2,+4$ e +6
d) $+3,+1,+5$ e +6
e) $+3,+1,+5$ e +7

$3^{\text {a }}$ Questão: (FGV-SP) Dadas as seguintes espécies químicas: $\mathrm{H}_{2} \mathrm{~S}, \mathrm{SO}_{2}, \mathrm{H}_{2} \mathrm{SO}_{4}, \mathrm{H}_{2} \mathrm{SO}_{3}$ e $\mathrm{S}_{8}$, podemos dizer que o número de oxidação do enxofre (S) nessas substâncias é, respectivamente:
a) $+2,+2,+6,+6,-2$
b) $-2,+4,+6,+4,0$
c) $+2,+4,+4,+6,-2$
d) $+2,+4,+4,+4,0$
e) $-2,+2,+6,+4,0$

4ª Questão: (MACKENZIE-SP) O número de oxidação do S, B, P e N nas substâncias é, respectivamente: $\mathrm{A}_{2}\left(\mathrm{SO}_{4}\right)_{3}, \mathrm{Na}_{2} \mathrm{~B}_{4} \mathrm{O}_{7}, \mathrm{H}_{4} \mathrm{P}_{2} \mathrm{O}_{7}$ e $\mathrm{N}_{2}$
a) $-2,+12,+10,-3$
b) $+6,+3,+5,0$
c) $+18,0,+1,-6$
d) $+1,+4,+2,+2$
e) $+3,+3,+3,+3$

5a Questão: (VUNESP-SP) Nas substâncias $\mathrm{CaCO}_{3}, \mathrm{CaC}_{2}, \mathrm{CO}_{2}, \mathrm{C}$ (grafita) e $\mathrm{CH}_{4}$, os números de oxidação do carbono são, respectivamente: 

a) $-4,+1,+4,0,+4$
b) $+4,-1,+4,0,-4$
c) $-4,-2,0,+4,+4$
d) $+2,-2,+4,0,-4$
e) $+4,+4,+4,+4,+4$

- No Investimento, é explanado o conteúdo, onde foram mencionadas algumas substâncias simples e compostos, neutras ou na forma de íons;

- No Encontro, neste momento os sujeitos ganharam a descrição do Jogo Didático "Roleta do NOX" e vivenciar o jogo;

- Na Confirmação ou Desconfirmação, é bem como os estudantes são orientados a confirmar ou desconfirmar as inquietações iniciais sobre o NOX das substâncias;

- Na Revisão Construtiva, eles são convidados a cogitarem a respeito da temática, e as dificuldades que apresentam sobre alguns exemplos de NOX.

\section{DESCRIÇÃO DO JOGO - "Roleta do NOX”}

Em relação ao quantitativo de jogadores por jogo, pode-se jogar as seguintes maneiras:

- JOGADORES INDIVIDUAIS - jogando com 02 (dois) integrantes;

- JOGADORES EM DUPLAS - jogando com 04 (quatro) integrantes;

- JOGADORES EM GRUPOS - jogando com mais de 10 (dez) integrantes, formando-se 02 (dois) a 04 (quatro) grupos;

Esse jogo didático tem um objetivo de identificar o Número de Oxidação (NOX) de cada elemento químico, ou seja, substâncias simples e compostos de maneira que os discentes compreendam esta temática de forma lúdica. Utilizamos como orientação para construção deste jogo os estudos de Fonseca (2016).

Este jogo é formado por 01 (uma) roleta onde apresenta 08 (oito) divisões, como mostra as imagens abaixo: 


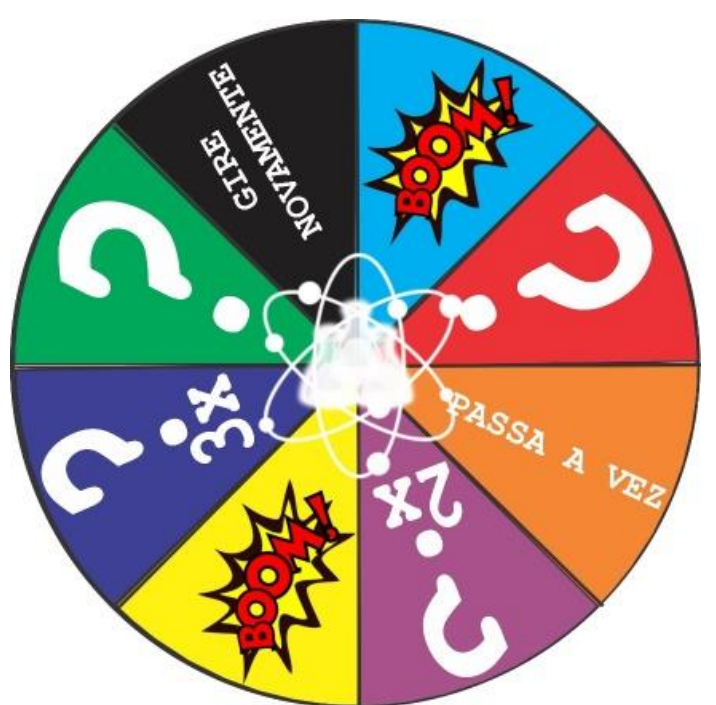

Figura 01: Diagramação da Roleta do NOX - Fonte: Própria

- A segunda e a sétima divisão é referente as perguntas com grau de dificuldade baixa, são as perguntas básicas para solucionar o NOX de elementos simples, onde valerá 10 (dez) pontos cada acerto, e cada erro perderá 05 (cinco) pontos.

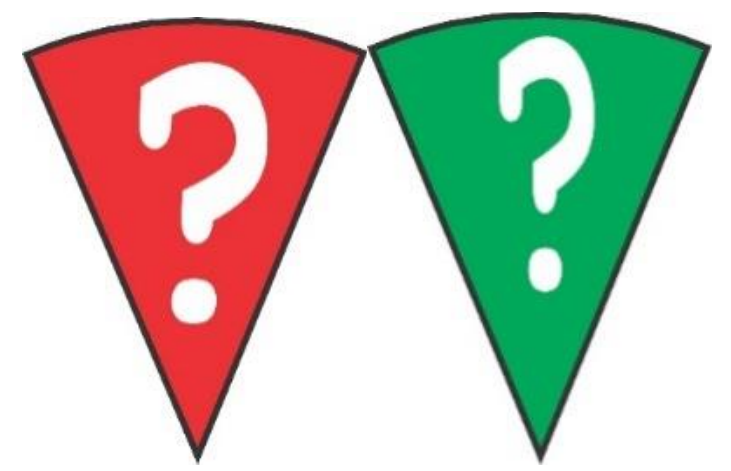

Figura 02: Diagramação das divisões da Roleta do NOX da segunda e da sétima parte (Pergunta Simples) Fonte: Própria

- Já a quarta e a sexta divisão é referente as perguntas com grau de dificuldade média e alta, onde o valor das pontuações duplicada (2x) e triplicada (3x) e essas perguntas são para solucionar o NOX de elementos de substâncias compostos de átomos neutros e íons.

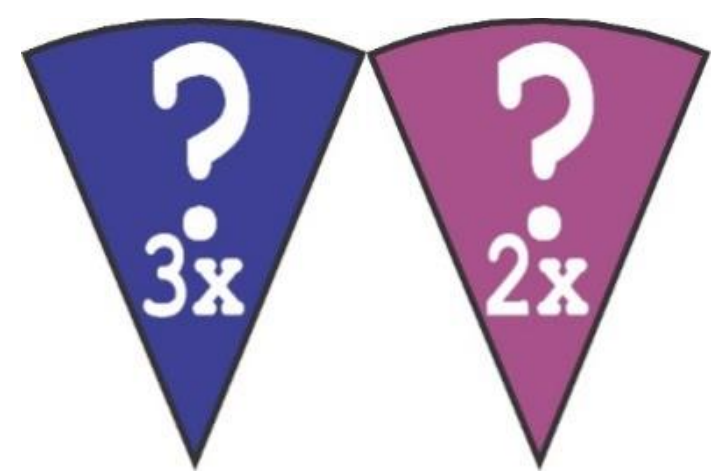

Figura 03: Diagramação das divisões da Roleta do NOX da quarta e da sexta parte (Pontuações duplicada e triplicada) - Fonte: Própria 
- A terceira parte é o "PASSA A VEZ", quando o(a) jogador(a) girar a roleta e a seta parar nesta parte, o(a) jogador(a) passará a vez para o(a) outro(a) jogador(a).

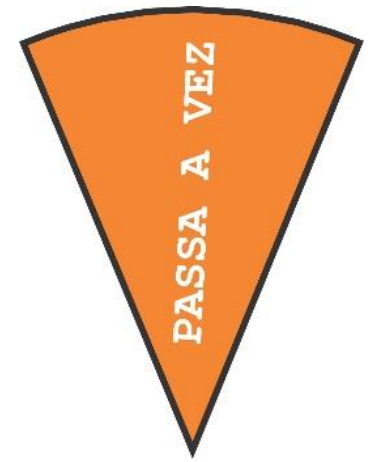

Figura 04: Diagramação das divisões da Roleta do NOX da terceira parte (Passa a vez) - Fonte: Própria

- Já a primeira e a quinta parte é a (bomba “Boom!”), quando o(a) jogador(a) girar a roleta e a seta parar nesta parte, o(a) jogador(a) passará a vez para o(a) outro(a) jogador(a).

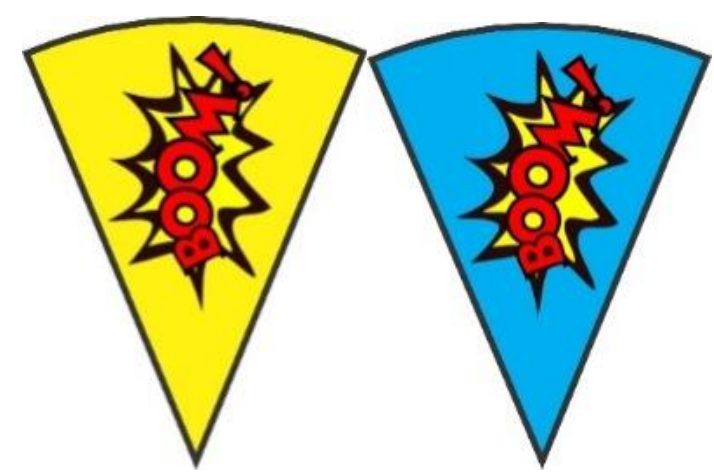

Figura 05: Diagramação das divisões da Roleta do NOX da primeira e da quinta parte (Bomba) - Fonte: Própria

- A oitava parte é o "GIRE NOVAMENTE", pois caso o(a) jogador(a) girar a roleta e a seta parar nesta parte, deverá girar novamente, caso caia neste mesmo local, o(a) jogador(a) perderá a vez.

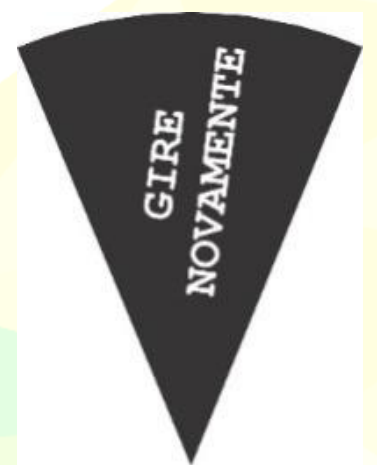

Figura 06: Diagramação das divisões da Roleta do NOX da oitava parte (GIRE NOVAMENTE) - Fonte: Própria

- As perguntas da Roleta do NOX baseado nos níveis de dificuldades, como perguntas simples com grau de dificuldade baixo são as cartas (vermelha e verde), e com grau 
médio e alto são as cartas (roxo e azul), cada cor de perguntas apresenta 24 (vinte e quatro) perguntas.

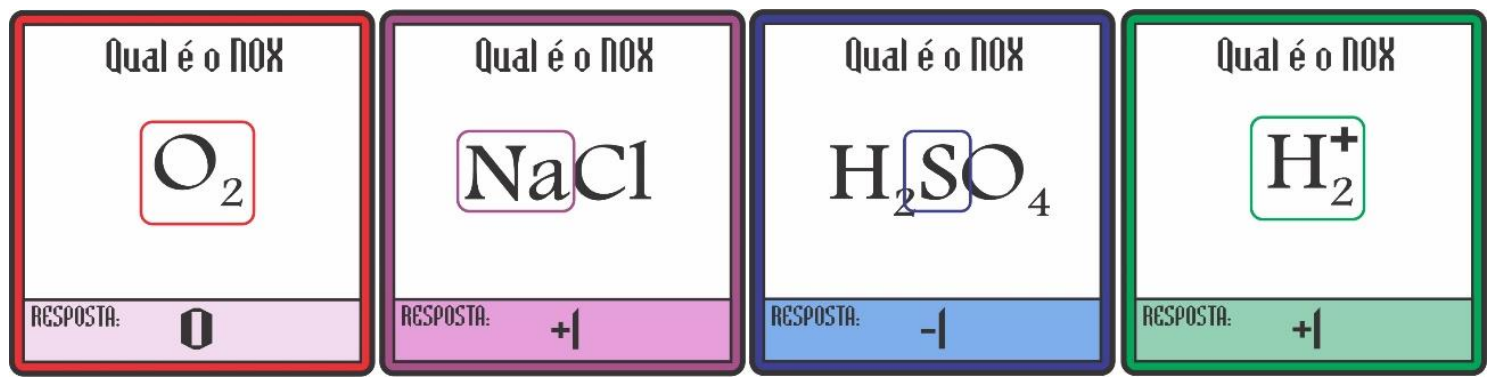

Figura 07: Diagramação das perguntas baseados em seus níveis de dificuldade da Roleta do NOX-Fonte: Própria

\section{REGRA DO JOGO}

Segue abaixo as orientações de formação de grupos por quantidade de alunos:

$\checkmark$ Após a formação dos grupos, para começar todos os integrantes tira "zerinho ou um”, ou "numera em papel a quantidade de membros, quem tirar o número 01 (um) inicia a partida, e os demais segue as numerações sucessivamente;

$\checkmark$ Para iniciar, gira a roleta, se cair a parte com a PERGUNTA VERMELHA ePERGUNTA VERDE, o(a) jogador(a) deverá pegar a caixa de perguntas VERMELHA, e o adversário irá perguntar, caso acerte ganha 10 (dez) pontos, caso erre perde 5 (cinco) pontos;

$\checkmark$ Se durante a vivência do jogo, cair a parte LARANJA onde tem PASSA A VEZ, o jogador não joga;

$\checkmark$ Se cair a parte de AZUL e AMIRELO, onde tem a BOMBA, o(a) jogador(a) deverá ir na caixa de bombas pegar a sua, e fazer o que está solicitando, caso contrário perderá 05 (cinco) pontos;

$\checkmark$ Se cair a parte que é a PERGUNTA ROXA e a PERGUNTA AZUL ESCURO, apresentará uma dificuldade a mais, porém os pontos do ROXO duplicará $(2 \mathrm{X})$ e do AZUL ESCUROtriplicará (3x).

$\checkmark$ Se cair a parte GIRE NOVAMENTE, deverá girar novamente, caso caia neste mesmo local, o(a) jogador(a) perderá a vez.

$\checkmark \mathrm{O}$ (a) docente irá estimar a quantidade de vezes em que os estudantes girarão as roletas, no mínimo 10 (dez) vezes que quanto mais exercitar, mais prático os estudantes estarão;

$\checkmark$ As equipes que acertar mais as perguntas, ganha a partida, o intuito não é vencedor, e sim, aquele que aprender mais. 


\section{RESULTADOS E DISCUSSÃO}

\section{Vivência do Ciclo da Experiência Kellyana (CEK) - Roleta do NOX}

Na Antecipação, inicia-se o ciclo da experiência, onde os estudantes receberam um questionário contendo 05 (cinco) perguntas sobre NOX.

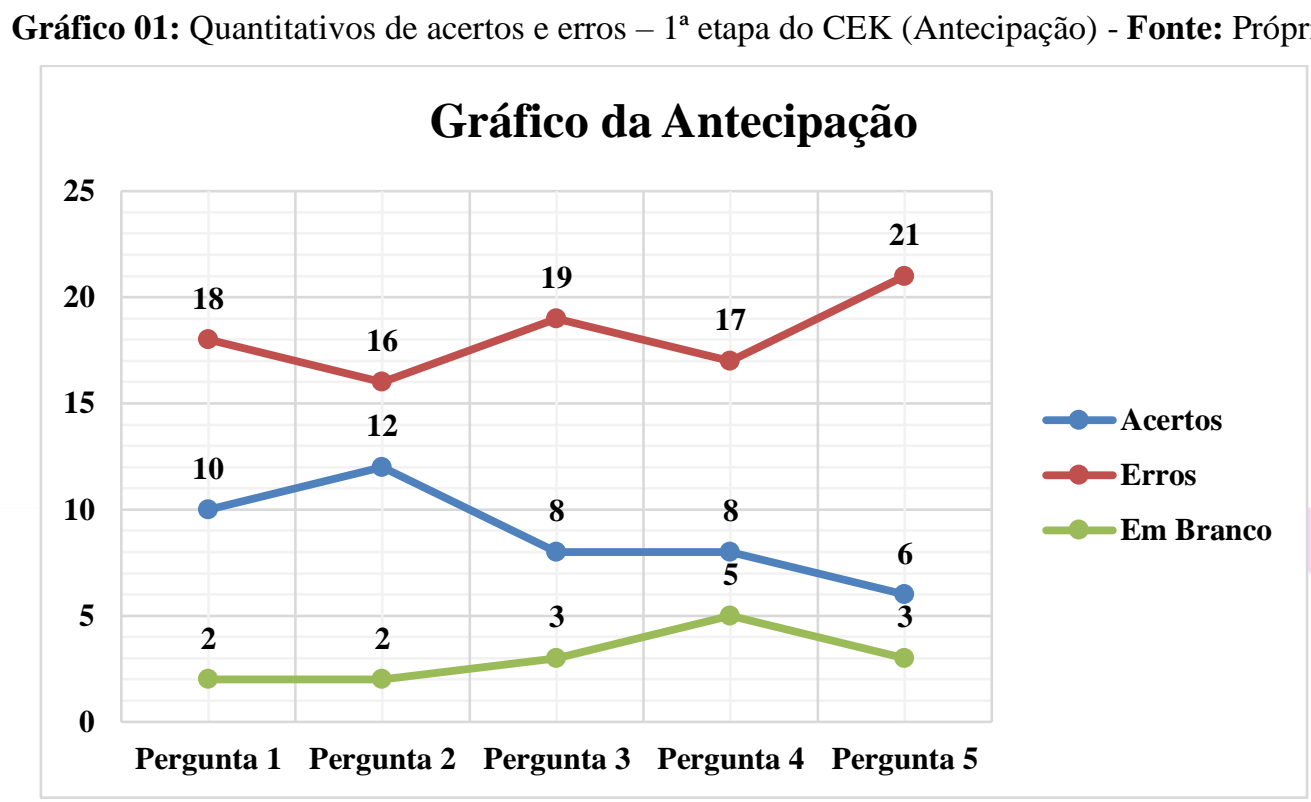

Na referente vivência pode-se perceber que a quantitade de erros chega a equivalente a $61 \%$, e o maior erro foi na P5, e percebemos que o erro está vinculado a dificuldade nas operações básicas.

No Investimento foi vivenciado ao lado das difuldades em que os estudantes apresentavam, onde foram citados alguns exemplos e foram resolvidos havendo assim uma troca entre professor-aluno e aluno-aluno.

No Encontro da experiência do jogo didático, os estudantes tiveram que fazer uma leitura da regra do jogo, para compreender cada passo a passo do jogo, assim facilitará o desenvolvimento e apreciação ao jogo, esta etapa teve em média 40 (quarenta) minutos.

Figura 08: Vivência da atividade lúdica - Fonte: Própria
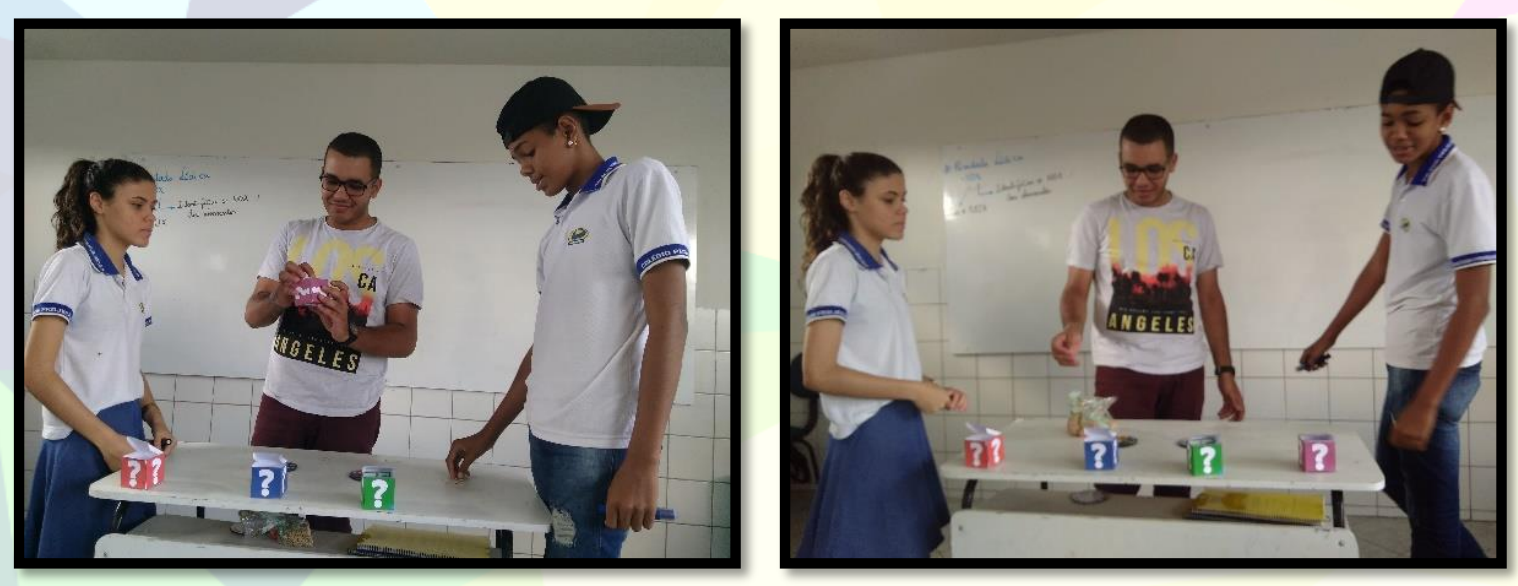
No jogo foram identificados algumas características lúdicas que alguns teóricos desta área discute, como afeição, interação, socialização, troca de experiência, novo olhar sobre a ciência, pensamento crítico, reflexivo e autônomo, e para afirmar que é um jogo didático é necessário que a função lúdica e educativo mantenha em equilíbrio.

$\mathrm{Na}$ Confirmação ou Desconfirmação verifica-se o resultado da vivência com o jogo didático (Roleta do NOX) e identifica se as ideias iniciais dos sujeitos modificaram ou não.

Gráfico 02: Quantitativos de acertos e erros - $4^{\mathrm{a}}$ etapa do CEK (Confirmação ou Desconfrmação) - Fonte: Própria

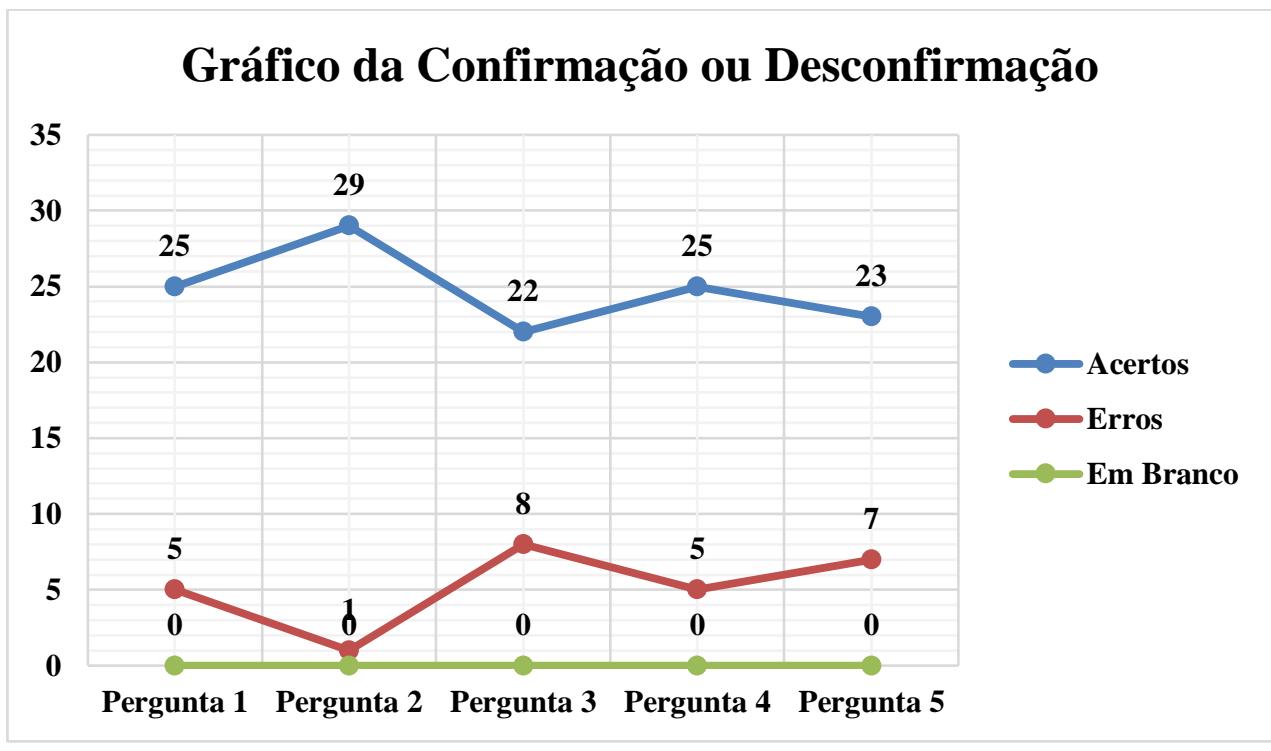

Na referente vivência pode-se perceber que a quantitade de erros chega a equivalente a $18 \%$, e o de acerto a $82 \%$, sendo predominante o acerto da $\mathrm{P} 2$, dessa forma podemos perceber que o uso de jogo didático nas aulas de química contribuiu para o processo de ensino e aprendizagem dos estudantes, e assim, cria uma ponte entre a química e a matemática. Os resultados coletados foram analisados pelo estudo de Fonseca (2016).

Na Revisão Construtiva foi realizado um momento de reflexão onde verificamos alguns tópicos abaixo: P1: Diante da oportunidade de ter uma aula com a utilização de jogo didático, de que forma você ver a disciplina de Química? sujeito 04: "fica mas dinamico a aula", e, sujeito 06: "eu acho que melhorou muito porque eu e meu grupo gostou muito". P2: Com o jogo didático ficou mais fácil de se envolver com o conteúdo de NOX? sujeito 14: "Sim, até a matemático ajudou, para mim o conteúdo era ruim por causa dos cálculos", e, sujeito 22: "claro, porque a gente se aproximou do conteúdo com a roleta".

\section{CONCLUSÕES}

Diante dessa pesquisa, podemos concluir que o uso de jogo didático no ensino de Química, no conteúdo de NOX (Número de Oxidação) trouxe vários benefícios para os 
estudantes e para o ensino, entre eles podemos destacar: (1) aproximação entre aluno-aluno e aluno-professor; (2) afeição e cognição; (3) prazer; (4) diversão; (5) compreensão dos conceitos químicos e matemáticos.

Este estudo mostrou o como importante é que o estudante procure sempre novas ferramentas de ensino procurando diferençar-se suas aulas e assim torná-las mais interessantes e atraentes para seus alunos, e o trabalho com o lúdico vem acolher essa necessidade como opção distinta, que pode ser utilizada como reforço de conteúdos antecipadamente desenvolvidos.

Por conseguinte, o emprego de novas alternativas didáticas no ensino de química é essencial no sentido de promover um ambiente distinto das aulas corriqueiras, pois irão instigar os estudantes a participação em sala de aula e ao mesmo tempo tirar o professor de sua zona de conforto.

\section{REFERÊNCIAS}

BRASIL. Orientações curriculares para o ensino médio - Ciências da natureza, matemática e suas tecnologias. Brasília: Ministério da Educação, Secretaria de Educação Básica, 2006.

CUNHA, M. B. Jogos no ensino de Química: considerações teóricas para sua utilização em sala de aula. Revista Química Nova na Escola, Vol. 34, p. 92-98, 2012.

DONDI, C.; MORETTI, M. A methodological proposal for learning games selection and quality assessment. British Journal of Educational Technology, 38. 2007.

FIALHO, N. N. Os jogos pedagógicos como ferramenta de ensino. 2008.

FREIRE, P. Pedagogia da autonomia: saberes necessários à prática educativa. 30. ed. São Paulo: Paz e Terra, 1996. (Coleção Leitura).

KELLY, G. A. A theory of personality: the psychology of personal constructs. New York: W.W. Norton, 1963.

KISHIMOTO, T. M. Jogo, Brinquedo, Brincadeira e a Educação. São Paulo: Cortez, 1996. $183 \mathrm{p}$.

LIMA, K. S. Compreendendo as concepções de avaliação de professores de Química através da teoria dos construtos pessoais. 163f. 2008. Dissertação (Ensino das Ciências).

Departamento de Educação, Pró-Reitoria de Pesquisa e Pós-Graduação, Universidade Federal Rural de Pernambuco, Recife, 2008.

M. S, BRITO. Jogo Arreug: estratégia para a elucidação das propriedades periódicas, IV Conedu Congresso Nacional da Edução 2017. 
RODRIGUES, M. O desenvolvimento do pré-escolar e o jogo. Ed Vozes - 2001 Petrópolis - Rio de Janeiro

SANTOS, A. B; QUIMARÃES, C. R. P. A utilização de jogos como recurso didático no ensino dezoologia. Rev. electrón. investig. educ. cienc. vol.5 no.2 agosto.2010.

SOARES, M.H.F.B. Jogos e atividades lúdicas no ensino de química: teoria, métodos e aplicações. IN:Anais, XIV Encontro Nacional de Ensino de Química. Departamento de química da UFPR .2008.

VIEIRA, W. E. S. Passa a vez das classificações carbônicas: um jogo didático auxiliador do processo de ensino-apredizagem de Química. V Conedu Congresso Naconal de Educação 2018. 